\title{
First Myanmar uniportal video-assisted thoracic surgery masterclass
}

\author{
Diego Gonzalez-Rivas ${ }^{1,2}$, Tint Zaw Oo ${ }^{3}$, Godwin Lew ${ }^{4}$, Ariel $\mathrm{Zhu}^{4}$ \\ ${ }^{1}$ Thoracic Surgery, Coruña University Hospital, UCTMI, Coruña, Spain; ${ }^{2}$ Department of Thoracic Surgery, Tongji University School of Medicine, \\ Shanghai 200120, China; ${ }^{3}$ Department of Thoracic Surgery, Yangon Specialty Hospital, Yangon, Myanmar; ${ }^{4}$ Fengh Academy of Minimally Invasive \\ Surgery, Fengh Medical Co., Ltd, Shanghai 200120, China \\ Correspondence to: Ariel Zhu. Fengh Academy of Minimally Invasive Surgery, Fengh Medical Co., Ltd, Room 213, 166 Lujiazui Ring Rd, Pudong, \\ Shanghai 200120, China. Email: aph.obd@fenghmedical.com.
}

\begin{abstract}
This article reports the first Myanmar uniportal VATS masterclass. Directed by Dr. Diego Gonzalez-Rivas, co-directed by Dr. Tint Zaw Oo, the two-day educational program was successfully held in Yangon Specialty Hospital (YSH) with live surgery and lectures. This masterclass is a unique event and pioneering course in Myanmar, which is open to every participant coming from different background and experiences in thoracic surgery. For the thoracic society in Myanmar, this program was significant and meaningful in a sense of helping more thoracic surgeons to embrace the newest of the less-invasive thoracic surgical techniques.
\end{abstract}

Keywords: Uniportal video-assisted thoracic surgery (uniportal VATS); masterclass; Myanmar

Received: 09 December 2019; Accepted: 19 February 2020; Published: 05 October 2020.

doi: 10.21037 /jovs.2020.02.09

View this article at: http://dx.doi.org/10.21037/jovs.2020.02.09

\section{Introduction}

"I have seen lots of Dr. Diego's operation videos online, but I would like to learn from him in person. Now, the dream came true", Dr. Hlwan Moe Htet expressed his gratitude in a short interview after this course. "It's amazing to meet Dr. Diego in this masterclass. I've heard of Dr. Diego's news of how he invented and practices Uniportal VATS. We had great interest in this technique and did some trails, which was successful but not so systematic. In this masterclass we have learnt important steps and almost everythingmuch more scientific and methodological"-Dr. Tint Zwo Oo, co-director of this masterclass, also expressed his sincere appreciation for the first Myanmar Uniportal VATS Masterclass, which was held in Yangon Specialty Hospital on October 3-4, 2019.

This masterclass is a unique event and pioneering course in Myanmar. About 30 participants from the whole country had a valuable experience in observing the live surgery and lectures, which were interactive, interesting, and overall educational. For Myanmar, a country with an extreme shortage of VATS faculty and educational resources, this masterclass is significant and meaningful in a sense of helping more thoracic surgeons to embrace the newest of minimally invasive thoracic surgical techniques.

\section{VATS history in Myanmar: a latecomer, yet well prepared for rapid learning}

In general, the history of uniportal VATS in Asia is considered by many to be short, particularly so as the VATS history in Myanmar, which was started in 2010 with an initial report of a VATS excision successfully performed in 2010. At that time, VATS procedures were just in the learning curve.

Over the past decade, the progress of thoracic surgery in Myanmar was not easy under the ever-changing and harsh socioeconomic conditions. As a matter of fact, the struggle to establish this specialty was certainly one of the most crucial challenges. Therefore, we can see a small rise in VATS, until the year of 2014 which saw several inaugural cases reported by major hospitals, as the government started 
Table 1 Pioneer VATS cases in Myanmar

\begin{tabular}{ll}
\hline Year & Pioneer VATS cases in Myanmar \\
\hline 2010 & First VATS biopsy in Yangon General Hospital \\
2014 & $\begin{array}{l}\text { First VATS thymectomy, lobectomy in Yangon } \\
\text { Specialty Hospital }\end{array}$ \\
2014 & VATS started in Mandalay General Hospital \\
2015 & VATS started in DSGH \\
2017 & Uniportal VATS trail by Dr. HIwan Moe Htet \\
\hline
\end{tabular}

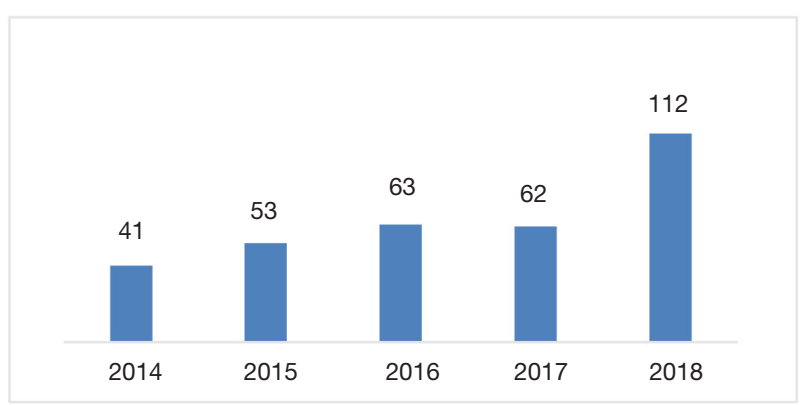

Figure 1 The number of VATS cases in Myanmar (2014-2018). VATS, video-assisted thoracic surgery.

supplying modern machines and instruments (pioneer cases in major hospitals were listed in Table 1).

Admittedly, Myanmar would be the latecomer of where the VATS had been arrived. However, the more recent progress in thoracic surgery has been significant, in terms of the growing numbers of VATS cases. Several factors contribute to the recent progress: experiences acquired during the last a few years, the interest and devotion of experienced surgeons, as well as the increasing impact of international thoracic societies which enhances academic exchanges (growing numbers of VATS cases were shown in Figure 1).

At the same time, uniportal VATS technique has begun to spread across Asia in an unprecedented speed. Several centers in the mainland China, Hong Kong, Korea and Singapore have grown to lead the trend in the vast continent of Asia. There is no doubt that the Asian experience in uniportal VATS aroused great enthusiasm from surgeons in Myanmar. It's a great time to facilitate the progress of Myanmar society to introduce new technique.

Based on these context, the first Myanmar uniportal VATS Masterclass was initiated by Dr. Diego Gonzalez-
Rivas. This masterclass has been enthusiastically supported by Dr. Tint Zaw Oo, the co-director of this program, who is currently leading the thoracic department that is run by limited human resources: one professor, one consultant and several medical officers only. Dr. Tint Zaw Oo has been devoted to education of a new generation of thoracic surgeons and to building up the specialty of minimally invasive thoracic surgery in Myanmar.

\section{Live surgery session: interactive, dynamic and overall educational (Figure 2, Video 1)}

The masterclass was open to everyone with different background, senior or junior surgeon, as well as medical students. More than 30 Participants had a valuable experience in observing the live surgery and discussing on these cases (Figure 3).

Three complex cases were successfully performed and demonstrated through Uniportal approach: Uniportal VATS for a complex right lower lobectomy with frozen hilum due to tuberculosis, subxiphoid Uniportal thymectomy (Figure 4), and S3 due to a dangerous arteriovenous malformation that was about to break with very thin wall. Undoubtedly, working at the elbow of the master is invaluable experience. "Having just started learning minimally invasive thoracic surgery, I thought the single port approach as a difficult technique, hard to learn. But this live demonstration changed my mind. It's not that hard to follow. It is possible to learn how to do like a standard case.", as told by some of the participants.

\section{Lecture Session: interesting, orientational and inspirational}

Started from a brief review of the "Journey of Uniportal VATS", Dr. Diego shared the origin and history of this technique, which has been subsequently widely spread from country to country and radically transformed lots of thoracic centers (Figure 5).

Also shared were some important topics:

* A variety of approaches and experiences of other centers with uniportal procedure (Figure 6);

* The technical aspects of lobectomy as well as more complex procedures;

* The progress and the future of minimally invasive thoracic surgery;

* The story behind uniportal VATS.

On this occasion, this is truly a young audience in their 


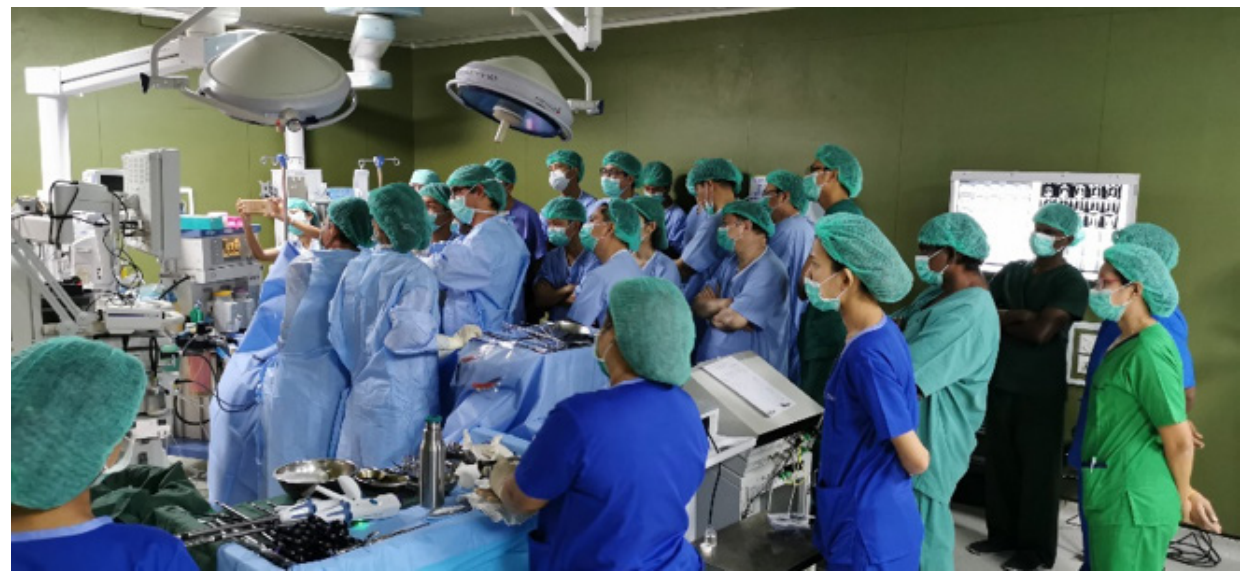

Figure 2 Dr. Diego Gonzalez-Rivas and participants during the live surgery.

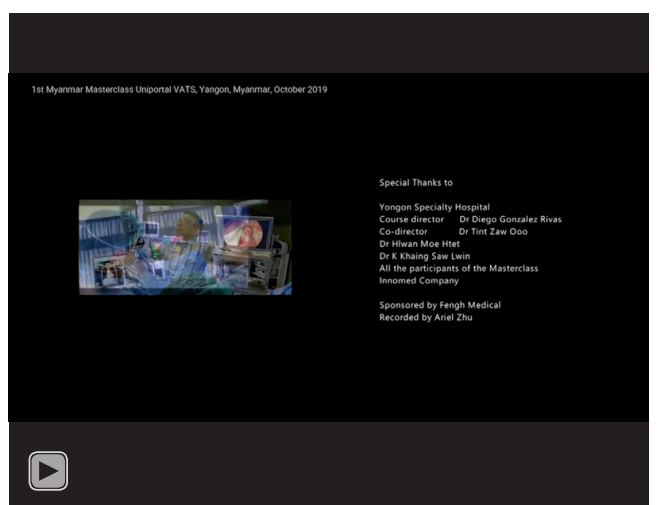

Video 1 First Myanmar uniportal VATS masterclass.

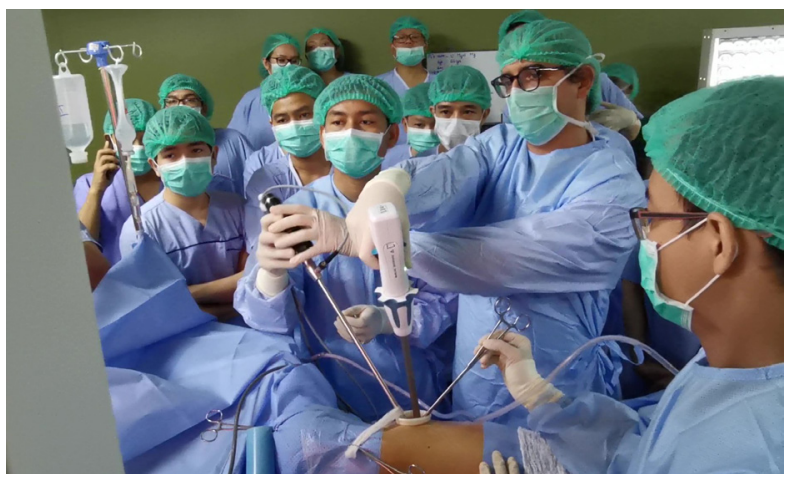

Figure 3 Teaching the instrumentation and position of devices in uniportal VATS. VATS, video-assisted thoracic surgery.

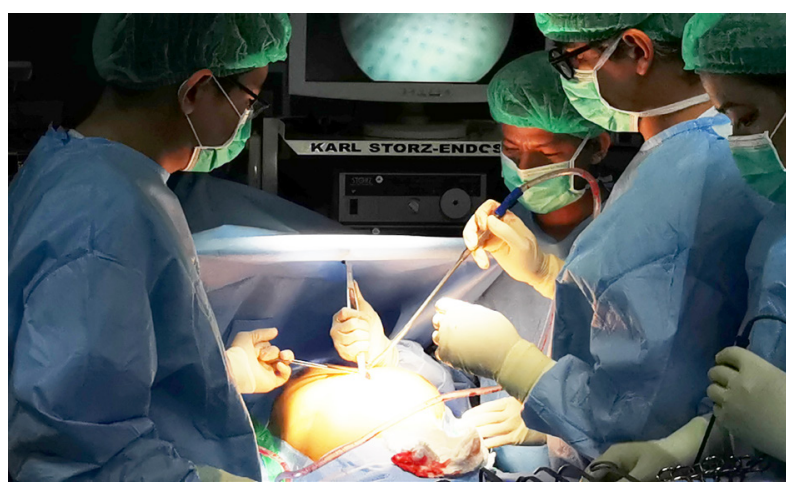

Figure 4 Teaching the set up during uniportal subxiphoid case.

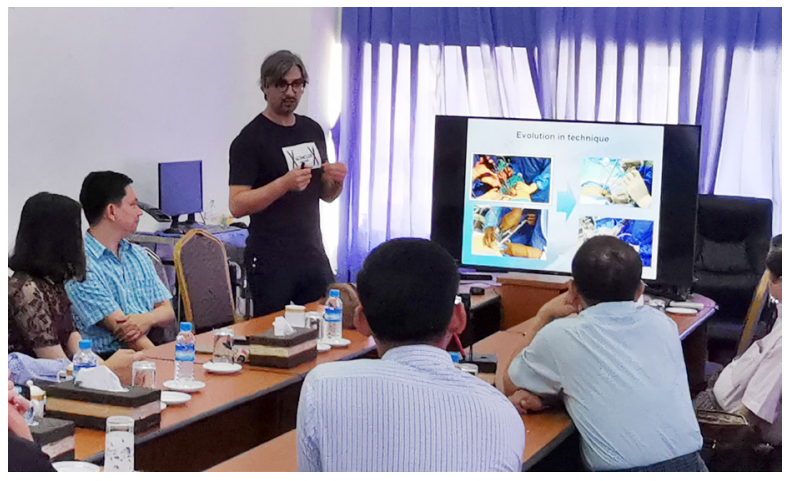

Figure 5 Introduction on different approaches of uniportal VATS during the lecture. VATS, video-assisted thoracic surgery. 


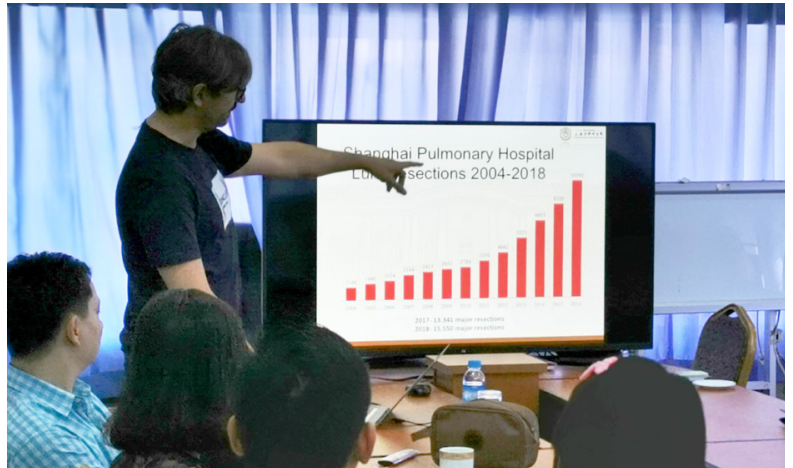

Figure 6 Introduction on the experience from other centers- the growth of uniportal VATS in China. VATS, video-assisted thoracic surgery.

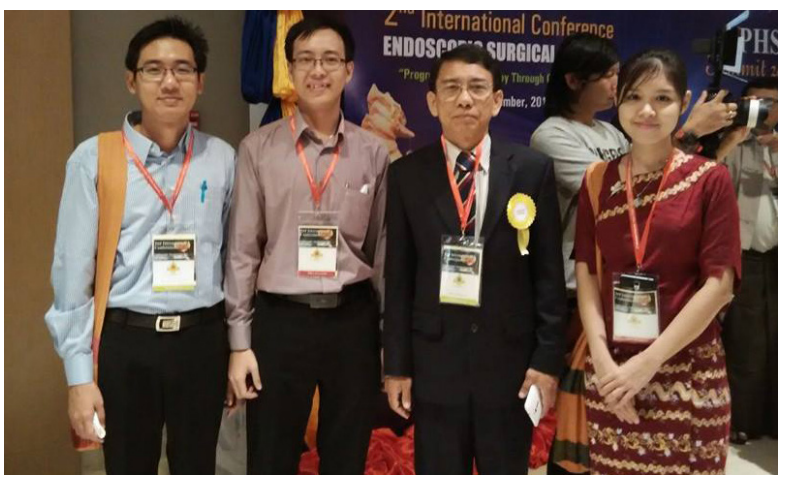

Figure 7 Dr. Tint Zaw Oo with young thoracic surgeons pursuing VATS and new techniques. VATS, video-assisted thoracic surgery.

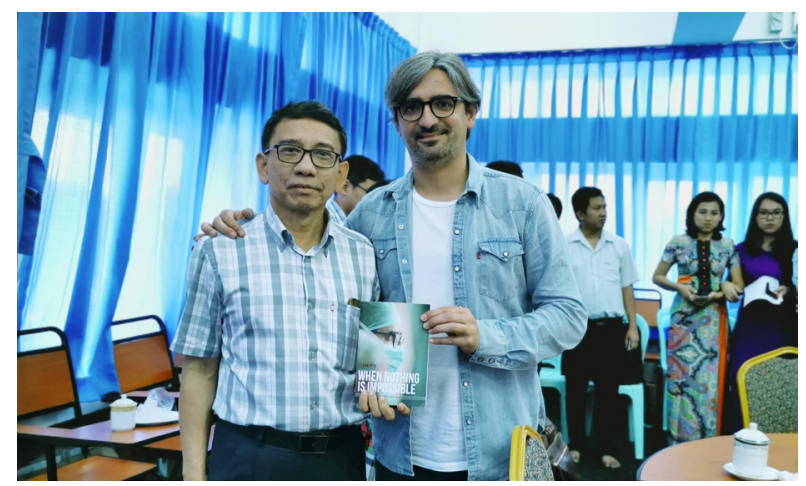

Figure 8 Sharing the book "When Impossible is Nothing" (an inspirational biography of Dr. Gonzalez-Rivas). learning stage, who are either in the pursuit of continuing education or undertaking medical degrees (Figure 7). There is no doubt that this masterclass opens a full spectrum of uniportal VATS that would be an orientation course for those who are interested in super specializing in this technique.

Also inspiring and motivating are the mottos and philosophy of uniportal teams all over the world "Think differently, get out of the comfort zone, measure the risk, be innovative, believe in an idea, fight for it and overcome the obstacles (Figure 8)". We are in the operating room-some younger, some older-but it makes no difference, because we share this philosophy of advancing, and this is the spirit that matters most.

\section{Discussion: continuing education programs for thoracic surgeons in Myanmar}

In general, the training of new young surgeons in thoracic surgery in developing countries is an urgent matter. The number of senior surgeons in some of these countries is far below that required to give a chance to the many patients needing thoracic surgery. At this point, Myanmar is an especially worth noting example where only less than 10 surgeons in 3 hospitals are be able to perform VATS for a population of 60 million. Yet, there is also a bright side. The country of Myanmar is full of capable, smart, hungry and hard-working people, increasingly better trained and resourced in this amazing era. The young generation of thoracic surgeons are sure to grow rapidly to be the cornerstone of thoracic surgery in this country (Figure 9).

This masterclass was supported by Fengh Academy of Minimally Invasive Surgery (FAMIS). As a leading Chinese enterprise in MIS industry, Fengh Medical initiated a global educational tour program in the beginning of 2019 . The great success of the first Myanmar Uniportal VATS Masterclass will be a model of continuing educational programs for helping young surgeons to embrace the newest techniques.

\section{Acknowledgments}

We thank Yangon Specialty Hospital (YSH), Thoracic 


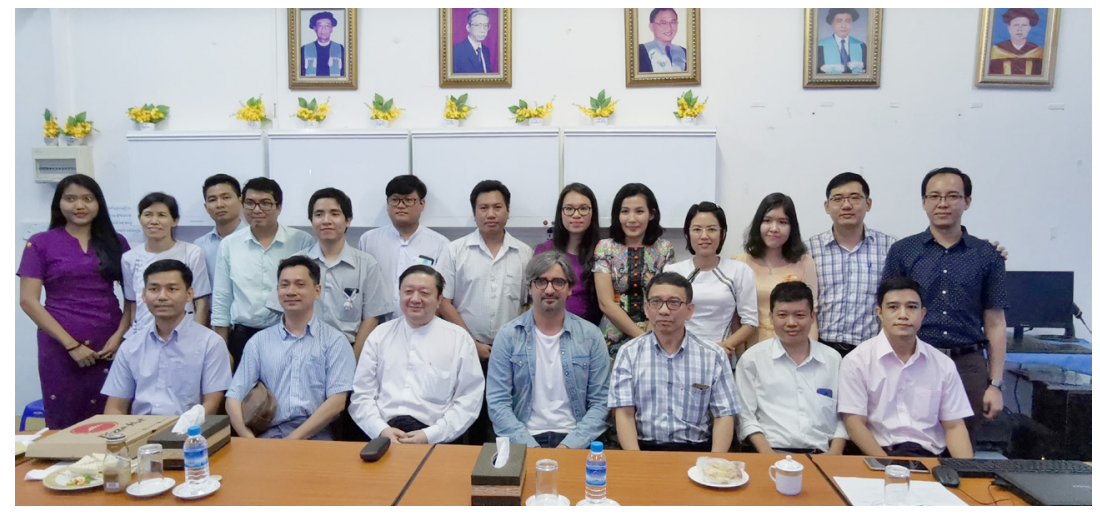

Figure 9 Participants of first Myanmar uniportal masterclass.

Department of YSH and all the participants for their support to this masterclass.

Funding: None.

\section{Footnote}

Provenance and Peer Review: This article was commissioned by the editorial office, fournal of Visualized Surgery for the series "Teaching Uniportal VATS". This article has undergone external peer review.

Conflicts of Interest: All authors have completed the ICMJE uniform disclosure form (available at https://jovs. amegroups.com/article/view/10.21037/jovs.2020.02.09/ coif). The series "Teaching Uniportal VATS" was commissioned by the editorial office without any funding or sponsorship. DGR served as the unpaid Guest Editor of the series and serves as an unpaid associate Editor-in-Chief of Fournal of Visualized Surgery. The authors have no other conflicts of interest.

doi: doi: 10.21037/jovs.2020.02.09

Cite this article as: Gonzalez-Rivas D, Zaw Oo T, Lew G, Zhu A. First Myanmar uniportal video-assisted thoracic surgery masterclass. J Vis Surg 2020;6:48.
Ethical Statement: The authors are accountable for all aspects of the work in ensuring that questions related to the accuracy or integrity of any part of the work are appropriately investigated and resolved. All procedures performed in studies involving human participants were in accordance with the ethical standards of the institutional and/or national research committee(s) and with the Helsinki Declaration (as revised in 2013). Written informed consent was obtained from the patients.

Open Access Statement: This is an Open Access article distributed in accordance with the Creative Commons Attribution-NonCommercial-NoDerivs 4.0 International License (CC BY-NC-ND 4.0), which permits the noncommercial replication and distribution of the article with the strict proviso that no changes or edits are made and the original work is properly cited (including links to both the formal publication through the relevant DOI and the license). See: https://creativecommons.org/licenses/by-nc-nd/4.0/. 